\title{
Avaliação de revestimentos à base de Inconel 625 depositados através do processo de soldagem GMAW em aço API 5L X70 utilizando Planejamento Fatorial
}

\section{Evaluation of Coatings of Inconel 625 deposited on API 5L X70 steel by GMAW welding process using Factorial Design}

\author{
Aureliano Xavier dos Santos ${ }^{1}$, Theophilo Moura Maciel' ${ }^{1}$, Renato Alexandre Costa de Santana ${ }^{2}$
}

\section{RESUMO}

A preocupação com o meio ambiente vem motivando diversas pesquisas sobre o uso de novos materiais para prolongar a vida útil de equipamentos que operam em ambientes agressivos no setor de petróleo. Uma das alternativas que vem sendo utilizada é a aplicação de revestimentos com materiais de alta resistência à corrosão por processo de soldagem. Objetivou-se neste estudo avaliar os efeitos dos diferentes parâmetros de soldagem sobre as características geométricas, diluição, microdureza, microestrutura e resistência à corrosão dos revestimentos com liga Inconel 625 depositados sobre chapa do aço API LL X70 utilizado em dutos para transporte de petróleo. Os parâmetros foram otimizados utilizando o planejamento experimental fatorial completo para analise dos parâmetros de processo, sendo os resultados analisados pela Metodologia de Superfície de Resposta (MSR). Foram realizados três depósitos com sobreposição de $1 / 2$ por processo de soldagem GMAW (Gas metal arc welding), seguido de corte transversal das amostras para a analise das caraterísticas geométricas e metalograficas. Para as analises de corrosão, as superfície do revestimento foram usinadas ficando com uma altura de 3 mm de acordo com a norma N-1707 da Petrobrás para revestimento. O comportamento eletroquímico da superfície do revestimento (Inconel 625) foi investigado a temperatura ambiente em solução de $\mathrm{NaCl}$ usando a técnica de polarização potenciodinâmica linear e espectroscopia de impedância eletroquímica. Para revelar a resistência à corrosão dos revestimentos, alguns parâmetros de caracterização relevantes foram analisados tais como: Resistência à polarização (Rp) e Potencial de corrosão (Ecorr). Os resultados apresentaram valores da diluição D (\%) variando de $12,77 \%$ a 24,88\% nos níveis máximo (18,99 KJ/cm) e mínimo $(8,34 \mathrm{KJ} / \mathrm{cm})$ de energia de soldagem, sendo os valores mais relevantes de 12,77 \%. Já com relação à resistência a corrosão, os resultados foram mais satisfatórios para o nível máximo de energia de soldagem.

Palavras-chave: GMAW; Revestimento; Corrosão.

\begin{abstract}
Concern for the environment has motivated several studies on the use of new materials to extend the life of equipment operating in harsh environments in the oil sector. One alternative that has been used is the application of coatings with high corrosion resistance welding process materials. The objective of this study was to evaluate the effects of different welding parameters on the geometric characteristics, dilution, microhardness, microstructure and corrosion resistance of the coatings with Inconel 625 alloy deposited on the API $5 \mathrm{~L}$ X70 steel used in oil pipelines to transport plate. The parameters were optimized using the factorial statistical experimental design for analysis of process parameters, and the results analyzed by Response Surface Methodology (RSM). Three deposits were carried out $1 / 2$ overwrite process GMAW (Gas Metal Arc Welding), followed by cross-sectional analysis of samples for the geometrical and metallographic characteristics. For the analysis corrosion, the coating surface being machined to have a height of $3 \mathrm{~mm}$ according to Standard N-1707 Petrobrás coating. The electrochemical behavior of the coating surface (Inconel 625) was investigated at room temperature in $\mathrm{NaCl}$ solution using the technique of linear potentiodynamic polarization and electrochemical impedance spectroscopy. To reveal the corrosion resistance of the coatings, featuring some important parameters were considered, such as: the polarization resistance (Rp) and the corrosion potential (Ecorr). The results showed dilution values $\mathrm{D}(\%)$ ranging from $12.77 \%$ to $24.88 \%$ in the maximum levels $(18.99 \mathrm{KJ} / \mathrm{cm})$ and minimum $(8.34 \mathrm{KJ} / \mathrm{cm})$ welding power, and the amounts the most important of $12.77 \%$. As to the corrosion resistance, the results were more satisfactory for the highest level of welding power.
\end{abstract}

Keywords: GMAW; Coating; Corrosion.

\footnotetext{
1 Universidade Federal de Campina Grande - Unidade Acadêmica de Engenharia Mecânica - Campina Grande (PB) - Brasil ZUniversidade Federal de Campina Grande - Unidade Acadêmica de Educação - Cuité (PB) - Brasil

Autor correspondente: Aureliano Xavier dos Santos - Universidade Federal de Campina Grande - Unidade Acadêmica de Engenharia Mecânica -

Campina Grande (PB) - Brasil

E-mail: aurelliano@yahoo.com.br

Recebido: 10/03/2015 Aprovado: 12/06/2015
} 


\section{INTRODUÇÃO}

No cenário brasileiro as atividades da exploração de petróleo vêm crescendo de forma intensa e se direcionam cada vez mais para águas profundas, geralmente localizadas distante da costa ${ }^{(1)}$. Impulsionada pelas novas descobertas das reservas do pré-sal, a produção estimada de petróleo e gás no Brasil deve praticamente dobrar até 2020, com investimentos de US\$236,5 bilhões no período entre 2012-2016 $6^{(2-4)}$. Com isso é necessário realizar melhorias continua dos materiais empregados nas malhas dutoviárias que são responsáveis pelo transporte de petróleo e seus derivados.

Dentre os materiais utilizados para a fabricação de tubulações, os aços de alta resistência e de baixa liga são os mais utilizados para essa finalidade. No Brasil os aços ARBL API 5L X70 são os mais usados na fabricação de gasodutos por apresentarem as seguintes propriedades: boa combinação de força e resistência, alta resistência mecânica, aliada à boa tenacidade, ductilidade e soldabilidade ${ }^{(5-7)}$. Porém, esses aços são sucintos a corrosão por tensão, permeação por hidrogênio e variação do $\mathrm{pH}$ dos fluidos transportados ${ }^{(5,8,9)}$.

Para aumentar a vida útil do ARBL API 5L X70 e redução dos custos com manutenções são utilizadas técnicas de proteção superficial como: metalização por aspersão térmica, galvanização, cladização, eletrodeposição, pintura, difusão, redução química (niquelação) e soldagem para revestimento ${ }^{(10)}$.

Dentre as técnicas de proteção de superfícies a do revestimento por soldagem é bem atrativa por oferecer a proteção através da aplicação de revestimentos unidos metalurgicamente ao substrato. Vários processos de soldagem vem sendo utilizados para este fim tais como: Processo a laser, (LBW), processos GTAW ou TIG com alimentação automática de arame (frio e quente), processo GMAW (MIG/MAG) e o processo à Plasma por Arco Transferido (PTA). Todos eles têm a finalidade de aplicação de uma camada protetora de um material com propriedades superiores sobre o substrato ${ }^{(11-15)}$.

Dos processos de soldagem ao arco elétrico, o GMAW possui grande importância na área de fabricação e reparo, o qual tem sido cada vez mais utilizado em linhas de montagem industriais do setor petrolífero, devido ao processo oferecer uma boa qualidade dos cordões de solda e com alta taxa de deposição e velocidade de soldagem $^{(12,13,16)}$.

Os revestimento por soldagem para proteção contra corrosão vem sendo bastante abordada nos últimos anos, utilizando-se aços inoxidáveis e as superligas de níquel, Inconel 625, como metal de adição para revestirem componentes e equipamentos da indústria do petróleo e gás natural. Apesar da aplicação da liga Inconel 625 por soldagem ser uma alternativa desejável, em função da liga apresentar elevada resistência em alta temperatura, boa soldabilidade,resistência à fluência, resistência à fadiga e excelente resistência à corrosão e oxidação em ambientes agressivoso custo da mesma é bastante elevada, sendo necessário que seja realizado um planejamento de estudos do processo para aplicação da liga ${ }^{(17,18)}$.

A otimização experimental de processos de soldagem é bem lenta, devido aos vários parâmetros de processos envolvidos e a muitos eventos não lineares ${ }^{(19)}$. O planejamento experimental fatorial se mostra superior aos métodos univariantes. Diante disto, os fatores são simultaneamente variados ao mesmo tempo e não um a cada vez como nos métodos clássicos, admitindo observar as interações dos fatores envolvidos na analise. Métodos univariantes não permitem avaliar as interações e por esta razão não são eficientes como técnicas de otimização ${ }^{(20-22)}$. A Metodologia de Superfície de Resposta (MSR) permite que o pesquisador aproxime o mecanismo desconhecido com um modelo empírico adequado, sendo assim a função que representa o modelo é denominado de Superfície de Resposta. A otimização dos dados experimentais para obter um bom ajustamento do modelo de superfície de resposta, requer conhecimentos básicos estatísticos do projeto experimental tais como: técnica de regressão e métodos de otimização elementar ${ }^{(19)}$.

Este artigo se propõe a analisar os efeitos dos parâmetros de soldagem (tensão, velocidade de alimentação e velocidade de soldagem) sobre as características geométricas (reforço, largura e índice de convexidade), diluição, microestrutura, microdureza e resistência à corrosão de revestimentos da superliga Inconel 625 depositados pelo processo GMAW a sobrechapas deaço API5LX70. Foi utilizado como ferramenta de otimização um planejamento experimental completo associado e a metodologia de superfície de resposta (MSR).

\section{MATERIAIS E PROCEDIMENTO EXPERIMENTAL}

\section{Materiais}

Como metal de base utilizou-se uma chapa de aço ARBL APIXLX70 com 19 mm de espessura. Para preparação dos corpos de prova a chapa foi cortada nas dimensões $(145 \times 60 \times 19) \mathrm{mm}$ através do processo oxi-acetileno. A liga de níquel, Inconel 625, ER NiCrMo-3, na forma de arame maciço com diâmetro de 1,2 mm foi utilizada como metal de adição. A mistura gasosa $(\mathrm{Ar}+25 \% \mathrm{He})$ foi usada como gás de proteção. As composições do metal de base e do metal de adição estão apresentadas nas Tabelas 1 e 2 , respectivamente.

\section{Procedimentos de Soldagem}

Os revestimentos foram depositados pelo processo de soldagem ao Arco Elétrico com Proteção Gasosa (GMAW - Gas Metal Arc Welding). A fonte de soldagem utilizada foi um modelo DIGI Plus A7 800 fabricado pela IMC Soldagem, contendo os seguintes acessórios: Fonte do tipo corrente contínua e tensão constante com capacidade de corrente máxima de $800 \mathrm{~A}$, sistema de aquisição de dados para o monitoramento dos parâmetros de soldagem e tartílope para deslocamento linear da tocha.

\section{Planejamento Experimental}

Para otimização dos experimentos foi utilizado um planejamento fatorial completo $2^{3}$, com 3 experimentos no ponto central, totalizando 11 experimentos. Os experimentos foram realizados 
Tabela 1: Composição química (\% em massa) para aço ARBL API XL X70.

\begin{tabular}{|c|c|c|c|c|c|c|c|c|c|}
\hline \multirow{2}{*}{ API 5L X70 } & $\mathrm{C}$ & $\mathrm{Si}$ & $\mathrm{Mn}$ & $\mathrm{P}$ & $\mathrm{S}$ & $\mathrm{Cr}$ & $\mathrm{Mo}$ & $\mathrm{Ni}$ \\
& 0,19 & 0,24 & 0,7 & 0,018 & 0,018 & 0,064 & 0,008 & 0,07 \\
\hline
\end{tabular}

Tabela 2: Composição química (\% em massa) para Inconel 625 (ER NiCrMo-3).

\begin{tabular}{|c|c|c|c|c|c|c|c|c|c|c|c|c|c|}
\hline ER NiCrMo -3 & $\mathrm{C}$ & $\mathrm{Si}$ & $\mathrm{Mn}$ & $\mathrm{P}$ & $\mathrm{S}$ & $\mathrm{Cr}$ & $\mathrm{Mo}$ & $\mathrm{Ni}$ & $\mathrm{Al}$ & $\mathrm{Cu}$ & $\mathrm{Ti}$ & $\mathrm{Fe}$ & $\mathrm{Nb}+\mathrm{Ta}$ \\
\hline & 0,1 & 0,5 & 0,5 & 0,020 & 0,015 & $20,0-23,0$ & $8,0-10,0$ & 58 & 0,4 & 0,5 & 0,4 & 3,82 & $3,15-4,15$ \\
\hline
\end{tabular}

em ordem aleatória, para evitar o erro sistemático, variando-se simultaneamente as variáveis independentes. As análises de regressão dos dados experimentais foram interpretadas utilizando-se o software Statistica 8 para estimar a resposta das variáveis dependentes. A Tabela 3 apresenta os valores reais e codificados da matriz de planejamento. Cada variável independente foi investigada para um nível alto $(+1)$ e baixo $(-1)$. Os experimentos do ponto central (0) foram incluídos na matriz e na análise estatística, para identificar o efeito de cada variável em função das características geométricas, diluição e resistência à corrosão.

As variáveis independentes (parâmetros de soldagem) dos experimentos foram a tensão (U), a velocidade de alimentação do arame (Va) e a velocidade de soldagem (Vs). Foram mantidos fixos: posição de soldagem (plana), ângulo de ataque da tocha de soldagem $\left(\theta=15^{\circ} \mathrm{com}\right.$ a vertical), sentido de soldagem (empurrando), polaridade corrente reversa (CC+), vazão do gás de proteção (25 L/min) e DBCP de $20 \mathrm{~mm}$. A deposição foi feita com três camadas de revestimentos, conforme a Fig. 1, utilizando uma sobreposição de $1 / 2$ da largura de cada cordão em cada corpo de prova utilizando uma temperatura de interpasse de $100{ }^{\circ} \mathrm{C}$.

\section{Caracterização geométrica e cálculo da diluição}

As amostras obtidas, após corte transversal, foram avaliadas quanto às características geométricas (largura e índice de convexidade $=\mathrm{R} / \mathrm{L}^{\star} 100 \%$ ) utilizando um paquímetro para as medições. Foi utilizada a média aritmética de três medições de cada uma das características geométricas citadas. Já para a medição o cálculo da diluição foi utilizado o software Image tool. A Fig. 2 mostra a representação esquemática da área do cordão de solda, indicando à largura $(L)$, reforço $(R)$, penetração $(P)$, área da zona fundida $\left(A_{f}\right.$ ), área do metal depositado $\left(\mathrm{A}_{\mathrm{d}}\right)$.

A diluição é o percentual do metal de base que se dissolve junto ao metal de adição formando a composição química do metal de solda e pode ser medida em função da área do metal de base fundida, conforme a Fig. 2 e a sua quantificação feita de acordo com a Equação 1.

$$
D(\%)=\frac{A_{f}}{A_{f}+A_{d}} \times 100
$$

\section{Caracterização Microestrutural e Microdureza}

Para a análise microestrutural e de microdureza foram retiradas espécimes com $10 \mathrm{~mm}$ de largura do centro dos cordões dos revestimentos. Para avaliação da microestrutura por microscopia ótica, as amostras foram submetidas à preparação metalográfica, a qual foram
Tabela 3: Níveis reais e codificados dos fatores em estudo

\begin{tabular}{|c|c|c|c|}
\hline \multirow{2}{*}{ Variáveis Independentes } & \multicolumn{3}{|c|}{ Níveis } \\
\cline { 2 - 4 } & -1 & 0 & -1 \\
\hline Tensão $(\mathrm{V}) \mathrm{U}$ & 26 & 29 & 32 \\
\hline Vel.de alimentação $(\mathrm{m} / \mathrm{min}) \mathrm{Va}$ & 6 & 7,5 & 9 \\
\hline Vel.de soldagem $(\mathrm{cm} / \mathrm{min})$ Vs & 20 & 25 & 30 \\
\hline
\end{tabular}

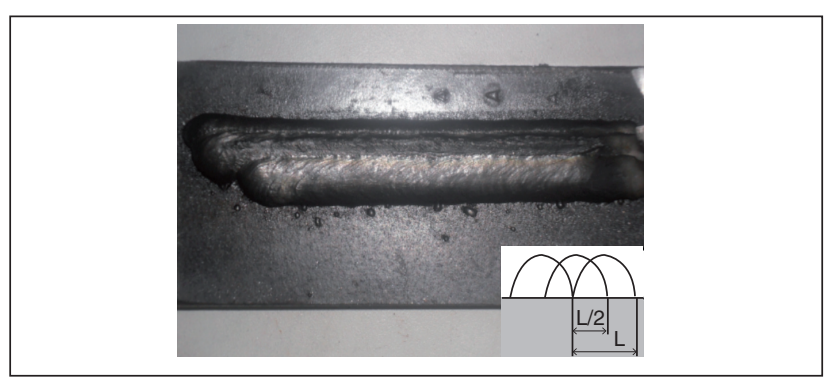

Figura 1: Revestimento GMAW com três passes com sobre posição 1/2.

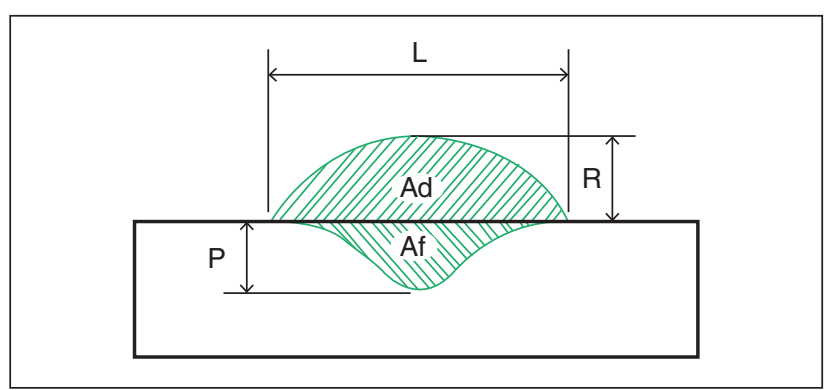

Figura 2: Representação esquemática da seção transversal do revestimento soldado(7).

lixadas com lixas de granulação de 200 até $1200 \mu \mathrm{m}$, seguido de polimento com alumina de 1 a $0,05 \mu \mathrm{m}$ e, por fim, foram atacados quimicamente com Nital a 2,0\% para realização da análise metalográfica. O levantamento dos perfis de microdureza Vicker consistiu de varredura em três linhas verticais, sendo traçado uma linha na seção transversal no centro dos cordões e as demais na região da sobreposição dos mesmos, em pontos do Metal de Solda (MS), Zona termicamente afetada (ZTA) e metal de base (MB), aplicando uma carga de $100 \mathrm{~g}$ por 15 segundos a $0,20 \mathrm{~mm}$ de cada endentação, sendo no total 30 endentações, conforme ilustrado na Fig. 3.

\section{Análise de corrosão}

Antes da realização da análise de corrosão dos revestimentos, a superfície das amostras foram usinados por aplainamento, ficando com uma altura fixa de $3 \mathrm{~mm}$ conforme norma N-1707 da Petrobras para revestimento ${ }^{(23)}$. As medidas eletroquímicas de corrosão foram conduzidas em uma célula eletroquímica de três 


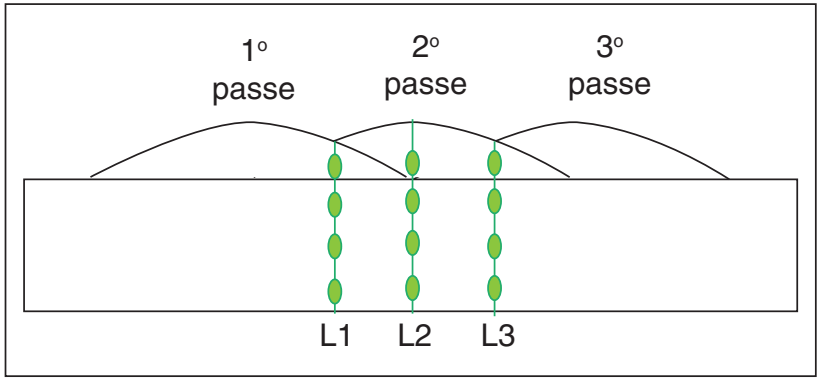

Figura 3: Disposição das endentações de microdureza.

eletrodos. Foram utilizadas as medidas de polarização potenciodinâmica linear (PPL) e espectroscopia de impedância eletroquímica (EIE) utilizando o equipamento Potenciostato/Galvanostato PG STATE30 da Autolab com auxílio de uma placa de interface PCI instalada em um computador, que possui o software, NOVA 1.9, para a aquisição de dados. O eletrodo de referência utilizado foi o prata/cloreto de prata $(\mathrm{Ag} / \mathrm{AgCl})$. O contra eletrodo foi um fio de platina em forma de espira. As análises de corrosão eletroquímica foram conduzidos no meio corrosivo contendo $60 \mathrm{ml}$ de solução $\mathrm{NaCl} 0,1 \mathrm{M}$ a temperatura ambiente. Para indicar a resi stência à corrosão dos revestimentos obtidos pelo processo de soldagem, alguns parâmetros de caracterização relevantes foram analisados tais como: Resistência à polarização (Rp) e Potencial de corrosão (Ecorr).

\section{RESULTADOS E DISCUSSÃO}

\section{Avaliação das características geométricas e diluição}

Para avaliar as características geométricas e diluição dos revestimentos foi utilizando um planejamento experimental e a Metodologia de Superfície de Resposta (MSR), dessa forma, foi possível investigar a influência das variáveis independentes(tensão $\mathrm{U}(\mathrm{V})$, velocidade de alimentação $\mathrm{Va}(\mathrm{m} / \mathrm{min})$ e velocidade de soldagem $\left(\mathrm{V}_{\mathrm{s}}\right)$ ) e a forma de interação entre elas, bem como obter o valor das variáveis dependentes que maximizem os resultados esperados. A Tabela 4 apresenta a matriz de planejamento fatorial $2^{3}$ e os resultados experimentais das deposições por soldagem com

Tabela 4: Matriz de Planejamento fatorial $2^{3}$ e resultados relação as variáveis dependentes: reforço $\mathrm{r}(\mathrm{mm})$, largura $\mathrm{L}(\mathrm{mm})$, índice de convexidade IC $=\mathrm{r} / \mathrm{L}^{\star} 100 \%$, e diluição (D\%), quando se faz variar as variáveis independentes..

Diante dos resultados obtidos, foi feito a análise dos dados para obter um modelo de primeira ordem que relacione as variáveis dependentes: reforço $\mathrm{r}(\mathrm{mm})$, largura $\mathrm{L}(\mathrm{mm})$, índice de convexidade IC $=r / L^{\star} 100 \%$, e diluição (D\%), com as variáveis independentes estudadas. Os modelos estabelecidos para as variáveis dependentes estão representados pelas Equações 2, 3, 4, 5, onde os coeficientes em negrito são os efeitos estatisticamente significativos ao nível de $95 \%$ de confiança.

$$
\begin{aligned}
& r=4,8981-0,4112^{*} U+0,558^{*} V a-0,643^{*} V s+0,013^{*} \\
& U^{*} V a-0,113^{*} U^{*} V s-0,028^{*} V a^{*} V s-0,263^{*} U^{*} V a^{*} V s
\end{aligned}
$$

$\mathrm{L}=24,831-2,763^{*} \mathrm{U}+1,561^{*} \mathrm{Va}-1,873^{*} \mathrm{Vs}+0,031^{*}$ $U^{*} V a-0,323^{*} U^{*} V s-0,061^{*} V a^{*} V s-0,353^{*} U^{*} V a^{*} V s$

$I C=23,854-3,778^{*} U+0,111^{*} V a-0,775^{*} V s+0,211^{*}$

$U^{*} V a-0,972^{*} U^{*} V s+0,894^{*} V a^{*} V s-1,487^{*} U^{*} V a^{*} V s$

$$
\begin{aligned}
& D \%=17,220-2,075^{*} U+1,245^{*} V a-3,226^{*} V s+0,207^{*} \\
& U^{*} V a-0,628^{*} U^{*} V s-0,366^{*} V a^{*} V s+0,490^{*} U^{*} V a^{*} V s
\end{aligned}
$$

\section{Onde:}

$\mathrm{U}=$ Tensão; $\mathrm{Va}=$ velocidade de alimentação, $\mathrm{Vs}=$ velocidade de soldagem e $U^{\star} \mathrm{Va}$; $\mathrm{U}^{*} \mathrm{~V}$ s; $\mathrm{Va}^{\star} \mathrm{V}$ s e $\mathrm{U}^{\star} \mathrm{Va}{ }^{*} \mathrm{~V}$ s são as interações das variáveis.

\section{Efeitos das variáveis do processo sobre o reforço (r)}

Conforme resultados apresentados na Tabela 4, os valores de resposta para o reforço $\mathrm{r}(\mathrm{mm})$ foram superiores a $3 \mathrm{~mm}$, variando de 3,48 a $6,18 \mathrm{~mm}$, os quais estão de acordo com a norma N-1707 da Petrobrás que recomenda uma altura mínima líquida de $3 \mathrm{~mm}^{(23)}$. Com a variação de altura do revestimento foi necessário usinar as amostra para manter todas com $3 \mathrm{~mm}$ de altura, isto é com mesmo patamar. Observa-se no diagrama

\begin{tabular}{c|c|c|c|c|c|c|c|c|}
\hline \multirow{3}{*}{ Exp. } & \multicolumn{3}{|c|}{ Variáveis Independentes } & \multicolumn{5}{c|}{ Variáveis dependentes } \\
\hline 1 & $\mathrm{U}(\mathrm{V})$ & $\mathrm{Va}(\mathrm{m} / \mathrm{min})$ & $\mathrm{Vs}(\mathrm{cm} / \mathrm{min})$ & $\mathrm{r}(\mathrm{mm})$ & $\mathrm{L}(\mathrm{mm})$ & $\mathrm{D}(\%)$ & $\mathrm{IC}=100^{*} \mathrm{r} / \mathrm{L}(\%)$ \\
\hline 2 & 26 & 6 & 20 & 5,56 & 21,88 & 16,25 & 30,12 \\
\hline 3 & 32 & 6 & 20 & 4,41 & 28,7 & 22,22 & 21,11 \\
\hline 4 & 26 & 9 & 20 & 6,18 & 25,77 & 20,04 & 25,16 \\
\hline 5 & 32 & 9 & 20 & 6,14 & 31,3 & 24,88 & 22,94 \\
\hline 6 & 26 & 6 & 30 & 4,03 & 19,61 & 12,77 & 25,75 \\
\hline 7 & 32 & 6 & 30 & 3,48 & 23,72 & 14,26 & 18,80 \\
\hline 8 & 26 & 9 & 30 & 5,59 & 21,84 & 13,13 & 30,31 \\
\hline 9 & 32 & 9 & 30 & 4,04 & 27,49 & 17,42 & 18,26 \\
\hline 10 & 29 & 7,5 & 25 & 4,80 & 24,24 & 16,09 & 23,43 \\
\hline 11 & 29 & 7,5 & 25 & 4,75 & 24,15 & 16,15 & 24,06 \\
\hline
\end{tabular}


de Pareto, Fig. 4 (a), que a velocidade de soldagem, $V_{s}$ é o efeito de maior importância para variável de resposta reforço, estando com valor na coluna negativo, significando então que a maior altura do reforço (r) é atingida para os menores valores da velocidade de soldagem. A velocidade de alimentação vem em segundo lugar como modelo de maior relevância, seguido da tensão e da interação $\mathrm{U}^{\star} \mathrm{Va}^{\star} \mathrm{Vs}$.

Através das informações apresentadas, a superfície de resposta foi construída mantendo-se o valor da velocidade de soldagem fixa em $20 \mathrm{~cm} / \mathrm{min}$, variando os valores das variáveis: tensão, $U$, e velocidade de alimentação, Va. A Fig. 4(b) apresenta a superfície de resposta construída para o reforço $\mathrm{r}(\mathrm{mm})$. Nota-se que a máxima altura do reforço $(6,3 \mathrm{~mm})$ ocorre para valores de tensão $26 \mathrm{~V}$ e velocidade de alimentação $9 \mathrm{~m} / \mathrm{min}$. Este valor está próximo do valor experimental obtido no experimento 3 , nas mesmas condições que é de $6,18 \mathrm{~mm}$. Isso se deve ao fato da maior quantidade de material depositado por minuto, através da alta taxa de deposição e menor velocidade de soldagem, como também ao fato da tensão baixa favorecer a cordões estreitos consequentemente com reforço mais alto ${ }^{(24)}$. A Tabela 5 mostra os dados resultantes da análise de variância (ANOVA), teste F e coeficientes de determinação $\left(\mathrm{R}^{2}\right)$.

Pode-se concluir, observando os dados da Tabela 5, que o modelo apresentado na Equação 2 tem coeficiente de determinação $\left(\mathrm{R}^{2}\right)$ igual a $99,5 \%$ das variações obtidas explicado pelo modelo,

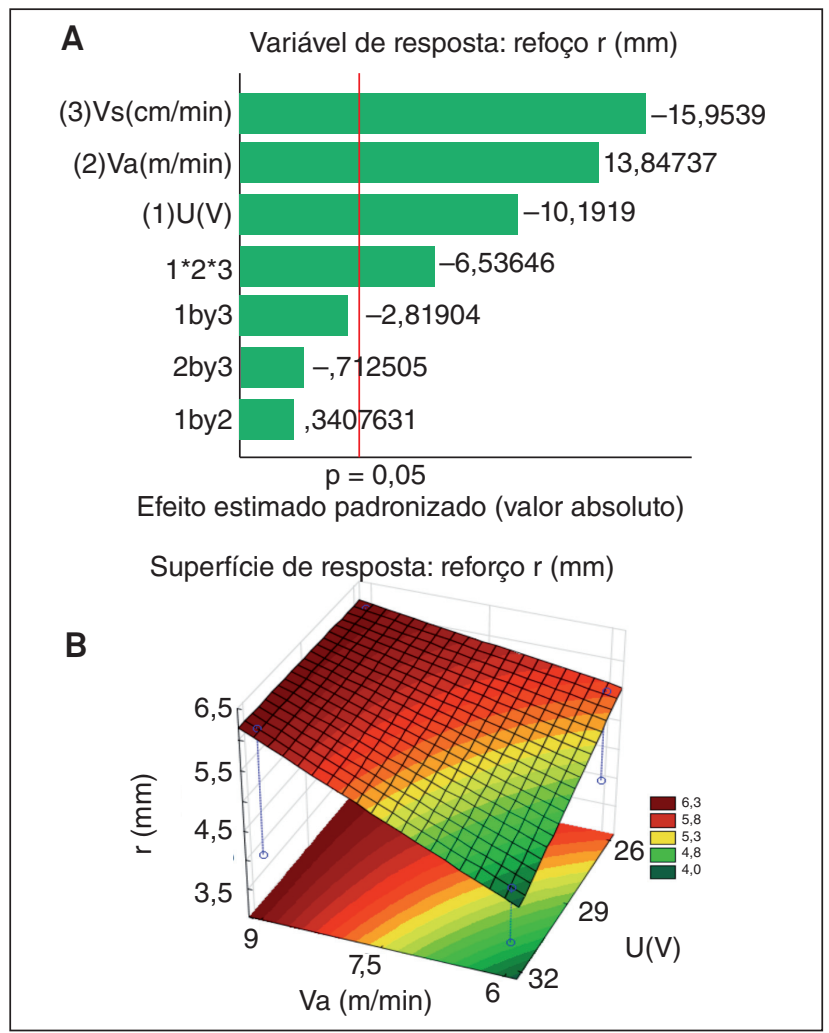

Figura 4: (A) Diagrama de Pareto dos efeitos para reforço $r$ $(\mathrm{mm})$ e (B) Superfície de resposta do reforço sob a influência da Tensão versus Velocidade de alimentação usando $20 \mathrm{~cm} / \mathrm{min}$ de Velocidade de Soldagem equação 16 , e com um valor da razão de $\mathrm{F}_{\text {calculado }}$ por $\mathrm{F}_{\text {tabelado }}$ de 9,66 , indicando que o modelo é estatisticamente significativo com 95\% de confiança devido ao fato do valor da razão entre os Fs ser maior que um, como também ser útil para fins preditivos em consequência de ser maior que quatro ${ }^{(25)}$.

\section{Efeitos das variáveis do processo sobre a largura (L)}

Observou-se os resultados obtidos para variável largura do revestimento que os valores variaram entre 19,61 a 31,3 $\mathrm{mm}$, conforme indicados na Tabela 4 . Conforme os resultados apresentados na Fig. 5(a), verifica-se que a Tensão, U, velocidade de alimentação, Va, e a velocidade de soldagem, Vs, mostraram influência estatisticamente significativa, enquanto que as interações das variáveis $\mathrm{U}^{\star} \mathrm{Va}$; $\mathrm{U}^{\star} \mathrm{Vs}$; $\mathrm{Va}^{\star} \mathrm{Vs}$ e $\mathrm{U}^{\star} \mathrm{Va}^{\star} \mathrm{Vs}$ não apresentaram influência estatística significativa apesar

Tabela 5: Resultados da ANOVA o reforço ( $r$ )

\begin{tabular}{|c|c|c|c|c|}
\hline Fator & SQ & GL & MQ & Fcalculado \\
\hline Regressão & 7,8341 & 7 & 1,12 & 85,92 \\
\hline Resíduo & 0,0391 & 3 & 0,01303 & \\
\hline F.Ajuste & 0,027409 & 1 & 0,02741 & \\
\hline Erro Puro & 0,0117 & 2 & 0,00583 & \\
\hline Total & 7,8732 & 10 & & \\
\hline$R^{2}$ & $99,5 \%$ & & & \\
\hline F tabelado & 8,89 & & Fcalc / Ftab $=$ & 9,66 \\
\hline
\end{tabular}

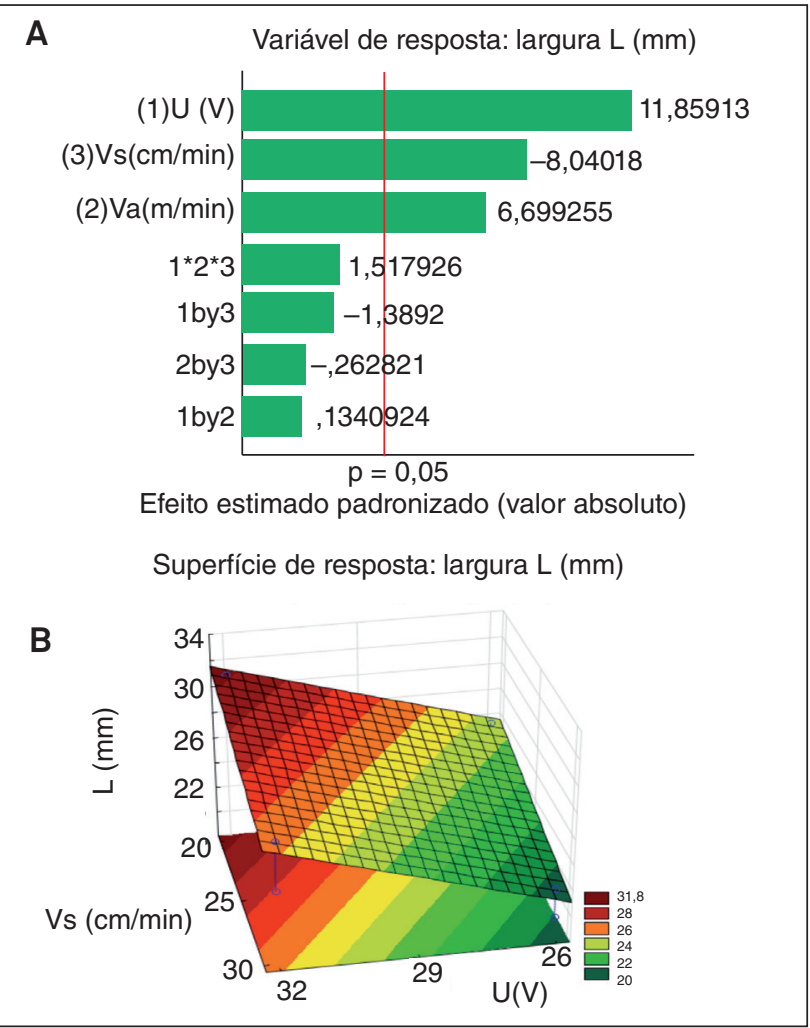

Figura 5: (A) Diagrama de Pareto dos efeitos para largura $L(\mathrm{~mm})$ e (B) Superfície de resposta da Largura sob a influência da Tensão versus Velocidade de soldagem usando $9 \mathrm{~m} / \mathrm{min}$ de Velocidade de alimentação. 
de ter apresentado o coeficiente de determinação $\mathrm{R}^{2}$ igual a $98,83 \%$.

Portanto, como a tensão e velocidade de alimentação apresentaram valores positivo nas colunas, significa então que a maior largura (L) é atingida para os maiores valores da tensão e velocidade de alimentação. Por outro lado, o valor negativo apresentado no gráfico na coluna da velocidade de soldagem, indica que largura máxima do revestimento é atingida em menores velocidades de soldagem. Assim, foi construída a superfície de resposta mantendo-se a velocidade de alimentação em $9 \mathrm{~m} / \mathrm{min}$, variando os valores das variáveis tensão e velocidade de soldagem. A superfície de resposta representada na Fig. 5(b) mostra que a máxima largura (L) (31,8 mm) é atingida para valores de tensão de $32 \mathrm{~V}$ e velocidade de soldagem de $20 \mathrm{~cm} / \mathrm{min}$. Este valor está próximo do valor experimental obtido no experimento 6 , nas mesmas condições que é de $31,3 \mathrm{~mm}$.

Os resultados mostram que os maiores valores da largura (L) são alcançados para os maiores valores de tensão, menores velocidades de soldagem e maior velocidade de alimentação. Os maiores valores da tensão se deve ao fato do maior comprimento do arco, resultar em uma coluna de plasma mais ampla em sua extensão proporcionando uma maior largura. Já para os menores valores de velocidade de soldagem promove um aumento na quantidade de material por unidade de comprimento. Por fim, a maior velocidade de alimentação influencia na largura devido ao aumento da taxa de deposição, ou seja, maiores taxas resultam em maior quantidade material depositado ${ }^{(24)}$. Na Tabela 6 constam os dados resultantes da análise de variância (ANOVA), teste F e coeficientes de determinação $\left(\mathrm{R}^{2}\right)$.

Portanto, de acordo com os resultados mostrados na Tabela 6, o modelo apresentado na Equação 3 tem coeficiente de determinação $\left(R^{2}\right)$ igual a $98,83 \%$ das variações obtidas explicado pelo modelo, Equação 3, e com um valor da razão de $\mathrm{F}_{\text {calculado }}$ por $\mathrm{F}_{\text {tabelado }}$ de 4,09, indicando que o modelo é estatisticamente significativo com 95\% de confiança devido ao valor da razão ser maior que um, com fins preditivos por apresentar valor da razão maior que quatro $^{(24)}$.

Tabela 6: Resultados da ANOVA para largura

\begin{tabular}{|c|c|c|c|c|}
\hline Fator & SQ & GL & MQ & Fcalculado \\
\hline Regressão & 110,5715 & 7 & 15,80 & 36,35 \\
\hline Resíduo & 1,3035 & 3 & 0,43449 & \\
\hline F.Ajuste & 1,25607 & 1 & 1,25608 & \\
\hline Erro Puro & 0,0474 & 2 & 0,02370 & \\
\hline Total & 111,8750 & 10 & & \\
\hline$R^{2}$ & $98,83 \%$ & & & \\
\hline F tabelado & 8,89 & & Fcalc / Ftab $=$ & 4,09 \\
\hline
\end{tabular}

\section{Efeitos das variáveis do processo sobre o índice de convexidade (IC)}

Os valores do índice de convexidade IC $=100^{*} \mathrm{r} / \mathrm{L}$ apresentados na Tabela 4, mostram uma variação de 18,26 a 30,31\%. A Fig. 6 (a) mostra que a tensão, $\mathrm{U}$, e a interação $\mathrm{U}^{\star} \mathrm{Va}^{\star} \mathrm{Vs}$, mostraram influência estatística significativa, enquanto que as demais variáveis e as interações entre elas não apresentaram influência estatística significativa. Entretanto apresentou o coeficiente de determinação $\mathrm{R}^{2}$ igual a $98,36 \%$.

Com base nestas informações apresentadas, foi construída a superfície de resposta mantendo-se a velocidade de alimentação em $9 \mathrm{~m} / \mathrm{min}$, variando os valores das variáveis tensões e da velocidade de soldagem. Pela Fig 6(b) representada para do índice de convexidade (IC $=r / l^{\star} 100 \%$ ) do revestimento, nota-se que o valor de $31 \%$ é obtido com valores de tensão $26 \mathrm{~V}$ e velocidade de soldagem de $20 \mathrm{~cm} / \mathrm{min}$. Este valor está próximo do valor experimental obtido no experimento 7 nas mesmas condições que é de 30,31\%.

Os resultados obtidos para o índice de convexidade estão de acordo com a literatura, a qual estabelece que valores próximos de $30 \%$ representam condições desejáveis para a relação largura (L) e reforço de cordão (r) ${ }^{(26)}$. Já alguns autores ${ }^{(26)}$, informam que o índice de convexidade deve sempre ser inferior a 30\%, como critério de qualidade. Na Tabela 7 mostra os dados resultantes da análise de variância (ANOVA), teste F e coeficientes de determinação $\left(\mathrm{R}^{2}\right)$.

Portanto, baseado nos dados da Tabela 7, o modelo apresentado na Equação 4 tem coeficiente de determinação $\left(R^{2}\right)$ igual a 98,36 \% das variações obtidas, apresentando um valor da razão de $\mathrm{F}_{\text {calculado }}$ por $\mathrm{F}_{\text {tabelado }}$ de 2,90, indicando que o modelo é estatisticamente significativo com $95 \%$ de confiança ${ }^{(25)}$.

Variável de resposta: índice de convexidade IC $=r / L^{*} 100 \%$

A

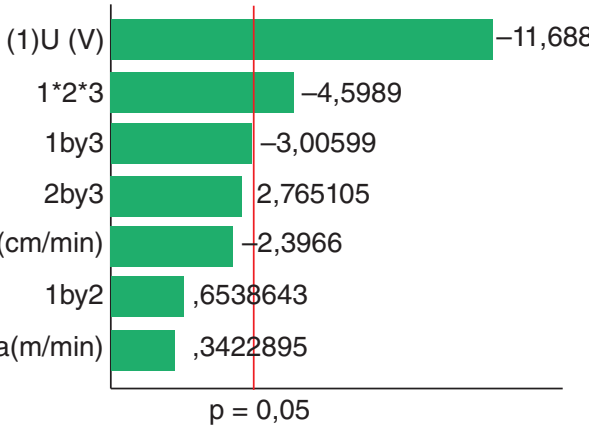

Efeito estimado padronizado (valor absoluto)

Superfície de resposta: índice de convexidade IC $=r / L * 100 \%$

B

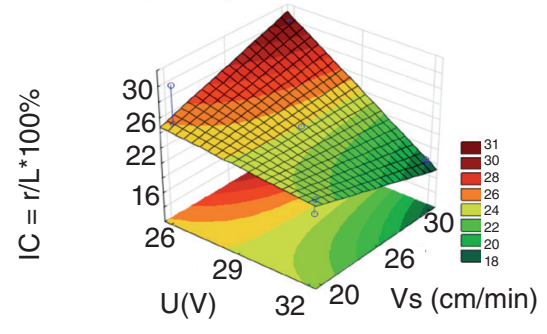

Figura 6: (a) Diagrama de Pareto dos efeitos para índice de convexidade (IC) e (b) Superfície de resposta do índice de convexidade sob a influência da Tensão versus Velocidade de soldagem usando $9 \mathrm{~m} / \mathrm{min}$ de Velocidade de alimentação. 
Tabela 7: Resultados da ANOVA para índice de convexidade

\begin{tabular}{|c|c|c|c|c|}
\hline Fator & SQ & GL & MQ & Fcalculado \\
\hline Regressão & 151,0802 & 7 & 21,58288 & 25,82 \\
\hline Resíduo & 2,5075 & 3 & 0,83585 & \\
\hline F.Ajuste & 1,200424 & 1 & 1,20042 & \\
\hline Erro Puro & 1,3071 & 2 & 0,65356 & \\
Total & 153,5877 & 10 & & \\
\hline$R^{2}$ & $98,36 \%$ & & & \\
\hline F tabelado & 8,89 & & Fcalc / Ftab $=$ & 2,90 \\
\hline
\end{tabular}

\section{Efeitos das variáveis do processo sobre a diluição (D\%)}

A Tabela 4 apresenta os resultados referentes à variável diluição $\mathrm{D}(\%)$, a qual variou de $12,77 \%$ a $24,88 \%$. Analisando os resultados apresentados na Fig. 7(a), verifica-se que a, velocidade de soldagem, $\mathrm{V}_{\mathrm{s}}$ e a tensão, $\mathrm{U}$, mostraram influência estatística significativa, enquanto que a velocidade de alimentação e as interações das variáveis não apresentaram influência estatística significativa. Entretanto apresentou o coeficiente de determinação $\mathrm{R}^{2}$ igual a $96,68 \%$. O valor negativo na coluna da velocidade de soldagem do diagrama de Pareto indica que à medida que a velocidade de soldagem diminui a diluição aumenta. Já para a tensão o sinal positivo da coluna indica que a medida tensão aumenta a diluição também aumenta.

A partir da análise estatística dos resultados para a variável diluição (\%) foi gerada a superfície de resposta, ver Fig. 7(b), pela qual observa-se que o menor percentual da diluição (12\%) ocorre para os valores da velocidade de soldagem de $30 \mathrm{~cm} / \mathrm{min}$ e tensão de $26 \mathrm{~V}$.

Estando esse valor próximo do valor experimental obtido no experimento 5 nas mesmas condições que é de 12,77\%. De acordo com os resultados apresentados na Fig. 7(b), com relação à velocidade de soldagem e a tensão do arco, os resultados mostram que a medida que aumenta a velocidade de soldagem e diminuí a tensão ocorre a diminuição na diluição. Isto se deve ao fato da velocidade ser inversamente e a tensão ser diretamente proporcional a energia de soldagem, proporcionando uma menor quantidade de calor imposto no substrato, e promovendo uma maior redução na área de metal depositado ${ }^{(27,28)}$.Na Tabela 8 apresenta os dados resultantes da análise de variância (ANOVA), teste $\mathrm{F}$ e coeficientes de determinação $\left(\mathrm{R}^{2}\right)$.

Os dados da Tabela 8, informa que o modelo apresentado na Equação 12 tem coeficiente de determinação $\left(R^{2}\right)$ igual a 99,31\% das variações obtidas explicado pelo modelo, equação 12, e com um valor da razão de $\mathrm{F}_{\text {calculado }}$ por $\mathrm{F}_{\text {tabelado }}$ igual a 1,40, indicando que o modelo é estatisticamente significativo com $95 \%$ de confiança ${ }^{(25)}$.

\section{Análise Metalográfica dos revestimentos}

\section{Microdureza}

As Figs. 8a e 8b mostram o perfil de microdureza das regiões do metal de solda (MS), zona termicamente afetada (ZTA) e metal de base (MB) para os revestimentos dos experimentos 4 e 5 . O experimento 4 aplicado com energia de soldagem $18,99 \mathrm{KJ} / \mathrm{cm}$, enquanto $8,34 \mathrm{KJ} / \mathrm{cm}$ para o experimento 5 . Os perfis de dureza foram na
Variável de resposta: diluição D (\%)

A

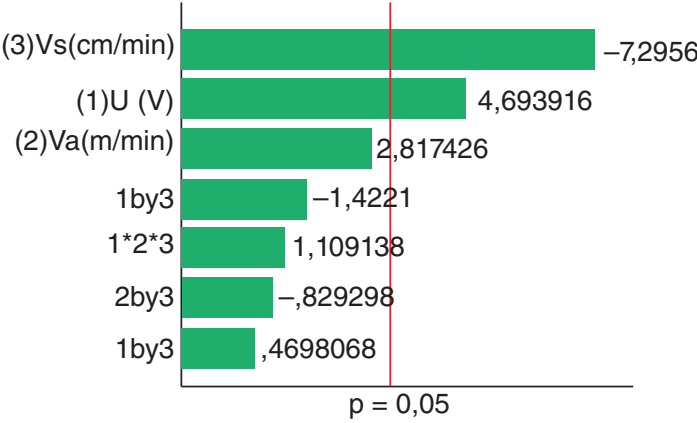

Efeito estimado padronizado (valor absoluto)

B Superfície de resposta: diluição D (\%)

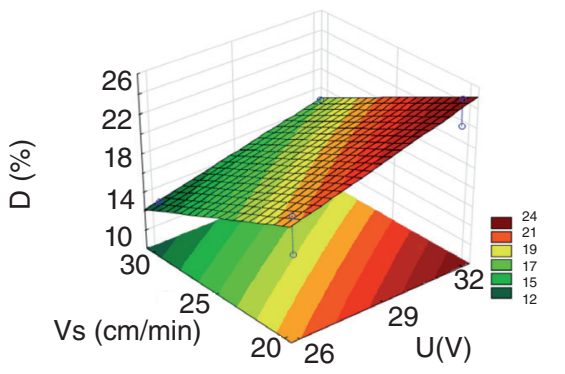

Figura 7: (a) Diagrama de Pareto dos efeitos para variável diluição D\% e (b) Superfície de resposta da diluição sob a influência da Tensão versus Velocidade de soldagem, fixando-se usando $9 \mathrm{~m} / \mathrm{min}$ de Velocidade de alimentação.

Tabela 8: Resultados da ANOVA para Diluição.

\begin{tabular}{|c|c|c|c|c|}
\hline Fator & SQ & GL & MQ & Fcalculado \\
\hline Regressão & 136,6583 & 7 & 19,52261 & 12,48 \\
\hline Resíduo & 4,6930 & 3 & 1,56434 & \\
\hline F.Ajuste & 4,682813 & 1 & 4,68281 & \\
\hline Erro Puro & 0,0102 & 2 & 0,00510 & \\
Total & 141,3513 & 10 & & \\
\hline R $^{2}$ & $99,31 \%$ & & & 1,40 \\
\hline F tabelado & 8,89 & & Fcalc / Ftab $=$ & 1 \\
\hline
\end{tabular}

seção transversal do cordão de solda. No eixo Y encontram-se os valores de dureza em $\mathrm{HV}$ e no eixo X verificam-se as endentações. Nota-se que o comportamento dos perfis de dureza em ambos experimentos são semelhantes nas regiões do MS e ZTA, apresentando um nível de microdureza superior no MS ao da ZTA. Em termos de valores médios, para a energia de soldagem $18,99 \mathrm{~kJ} / \mathrm{m}$ as durezas do MS e ZTA foram, respectivamente, $271 \mathrm{HV} \pm 11 \mathrm{HV}$ e $255,35 \pm 8,0 \mathrm{HV}$. E para energia $8,34 \mathrm{~kJ} / \mathrm{m}$, as durezas do MS e ZTA foram $350 \mathrm{HV} \pm 21 \mathrm{HV}$ e $269 \pm 8,0 \mathrm{HV}$, respectivamente.

Os resultados mostraram um aumento de 13,51 HV no valor médio da microdureza da ZTA ao reduzir a energia de soldagem de $\mathrm{H}=18,99 \mathrm{KJ} / \mathrm{cm}$ para $\mathrm{H}=8,34 \mathrm{~kJ} / \mathrm{cm}$. Energias de soldagem mais baixas resultam em taxas de resfriamento mais elevadas e, consequentemente, uma microdureza mais elevada na ZTA. Resultados encontrados na literatura obtiveram um aumento de 
$20 \mathrm{HV}$ na microdureza da ZTA quando reduziram a energia de soldagem de $15 \mathrm{KJ} / \mathrm{cm}$ para $11 \mathrm{~kJ} / \mathrm{cm}^{(28)}$. Este fato pode ser explicar em função da variação na taxa de resfriamento e, consequentemente, nos níveis de microdureza da ZTA.

\section{Microestrutura}

Nas imagens da Fig. 9, apresentam a variação da microestrutura na interface do revestimento com energia de soldagem $18,99 \mathrm{KJ} / \mathrm{cm}$.

A

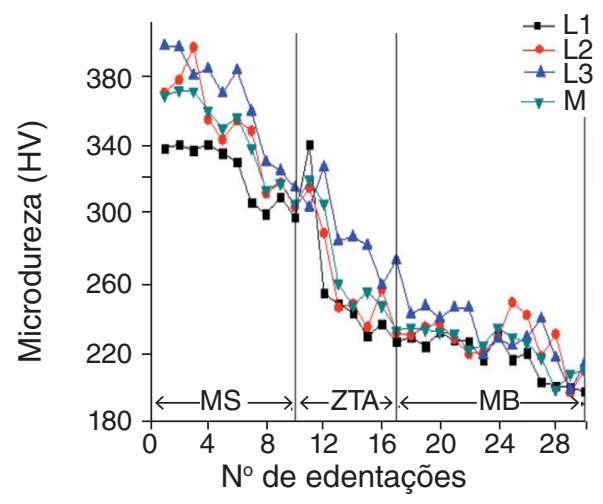

B

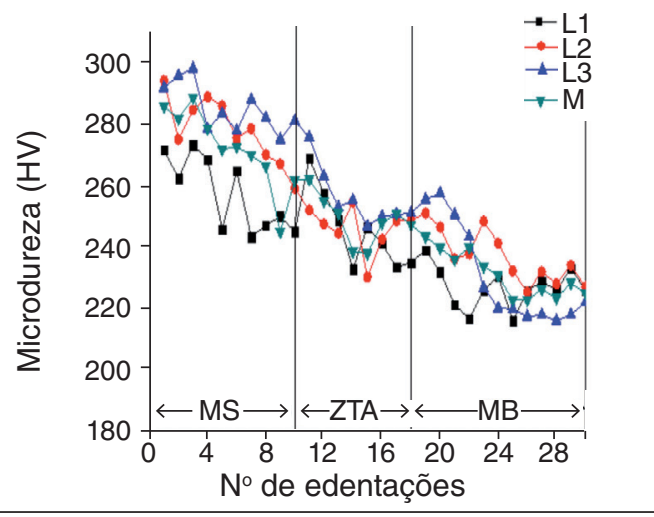

Figura 8: (a) Perfil de microdureza para $18,99 \mathrm{KJ} / \mathrm{cm}$ e (b) Perfil de microdureza em HV revestimento para $8,34 \mathrm{KJ} / \mathrm{cm}$.
A região da ZTA no $2^{\circ}$ passe (L2), ou seja, parte central do revestimento apresentou uma microestrutura mais refinada com grãos menores que as regiões entre passes, resultando menores valores de microdureza. Esse fato é devido à influência da energia de soldagem do $2^{\circ}$ passe depositado sobre o $1^{\circ}$ passe do revestimento e do $3^{\circ}$ passe depositado sobre o $2^{\circ}$ passe do revestimento. Isto também é influenciado pelo valor da sobreposição utilizada, $1 / 2$, visto que ao usar uma sobreposição de $1 / 3$ verificou resultado contrário, ou seja, maior refinamento da microestrutura nas regiões entre passes devido à linha de intersecção está mais distante do centro do revestimento, então o efeito da energia de soldagem não foi intenso na região central de tal forma que não surtiu efeito significativo para refinamento ${ }^{(29)}$.

Nas regiões entre os passes de revestimento (interseção), Linha L1 e L3 apresentaram uma microestrutura menos refinada, confirmando assim os maiores valores de microdureza conforme resultados apresentados anteriormente.

Analogamente aos revestimentos depositados com energia de soldagem $\mathrm{H}=18,99 \mathrm{KJ} / \mathrm{cm}$, também ocorreu refinamento de grãos da ZTA na região central, linha L2. Isto pode ser verificado na micrografia da Fig. 10. Este refino influenciou nos valores de microdureza e consequentemente reduziu a fragilidade nesta região.

\section{Avaliação da Corrosão dos Revestimentos depositados}

Os resultados da resistência à polarização $\left(\mathrm{R}_{\mathrm{p}}\right)$ e Potencial de corrosão $\left(\mathrm{E}_{\text {corr }}\right)$ corrosão foram obtidos com auxílio da matriz fatorial usada para a otimização das variáveis Tensão (U), velocidade de alimentação (Va) e velocidade de soldagem (Vs) e são mostrados na Tabela 9.

Diante dos resultados experimentais obtidos, ajustaram-se os dados para obter um modelo linear que relacione as variáveis dependentes: Resistência à polarização $\left(\mathrm{R}_{\mathrm{p}}\right)$, Potencial de Corrosão $\left(\mathrm{E}_{\text {corr }}\right)$, com as variáveis independentes estudadas. As Equações 6 e 7 representam os modelos estabelecidos para as variáveis

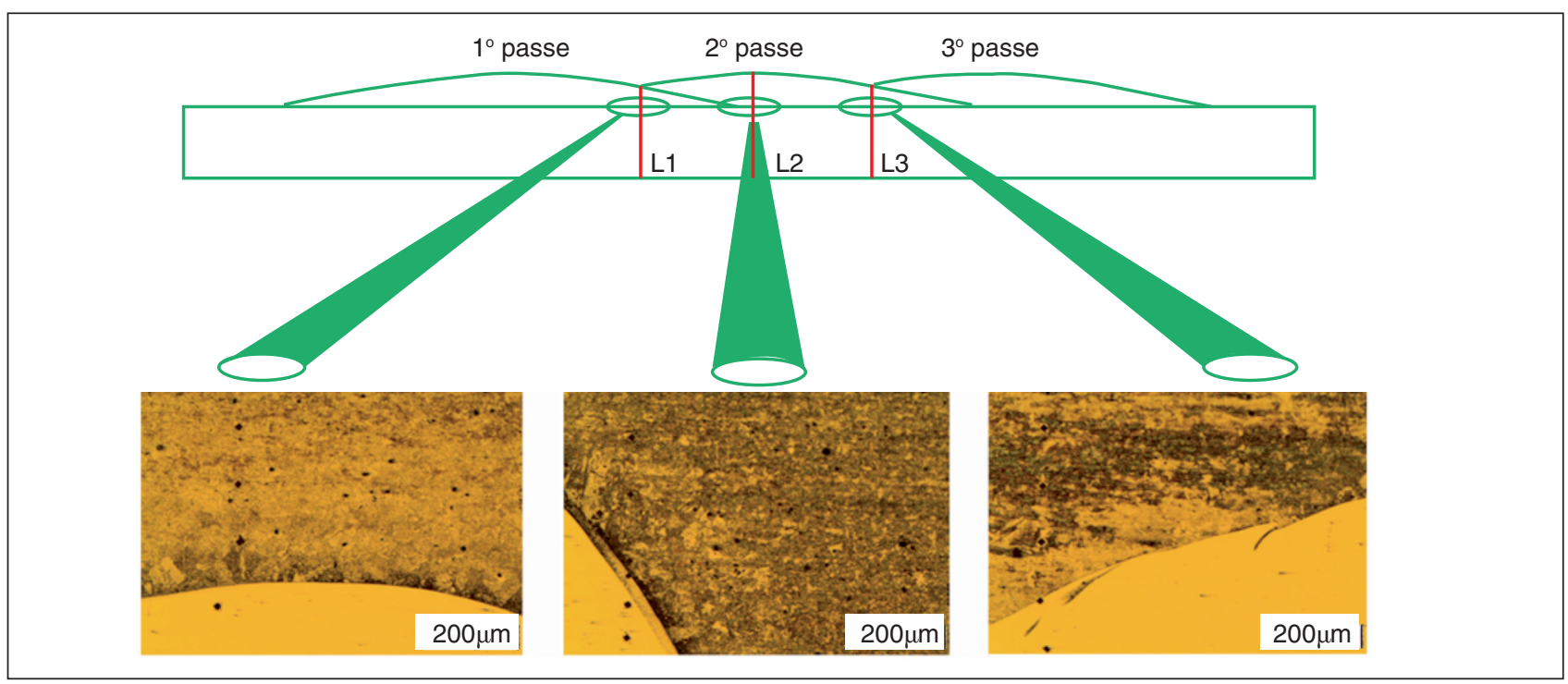

Figura 9: Imagens de microscopia óptica ao longo da interface MS/Substrato Experimento 4 (H=18,99 KJ/cm). Ampliação: 100x. 


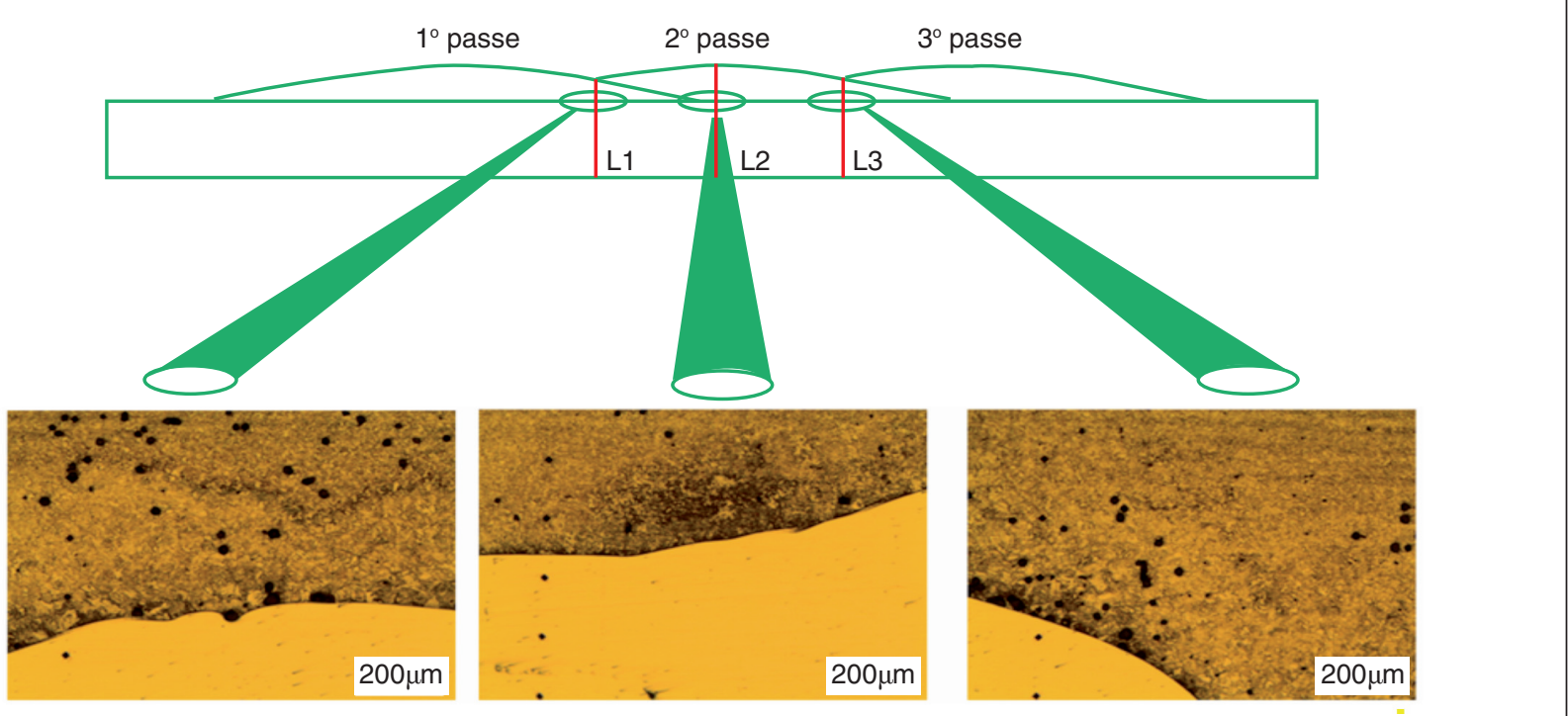

Figura 10: Imagens de microscopia óptica ao longo da interface MS/Substrato Experimento 5 (H=8,34 KJ/cm). Ampliação: 100x.

Tabela 9: Variáveis, valores para Resistência a Polarização e Potencial de Corrosão para o planejamento fatorial $2^{3}$.

\begin{tabular}{|c|c|c|c|c|c|c|c|c|}
\hline \multirow{2}{*}{ Exp. } & \multicolumn{3}{|c|}{ Variáveis Independentes } & \multicolumn{4}{|c|}{ Variáveis dependentes } & \multirow{2}{*}{$\mathrm{H}(\mathrm{KJ} / \mathrm{cm})$} \\
\hline & $U(V)$ & $\mathrm{Va}(\mathrm{m} / \mathrm{min})$ & Vs (cm/min) & $\operatorname{Rp}(\mathrm{K} \Omega)$ & Ecorr (V) & D (\%) & $\mathrm{Fe}(\%)$ & \\
\hline 1 & 26 & 6 & 20 & 247,87 & $-0,2834$ & 16,25 & 5,819 & 12,40 \\
\hline 2 & 32 & 6 & 20 & 333,01 & $-0,2285$ & 22,22 & 7,283 & 16,96 \\
\hline 3 & 26 & 9 & 20 & 304,45 & $-0,2557$ & 20,04 & 10,563 & 15,29 \\
\hline 4 & 32 & 9 & 20 & 375,56 & $-0,2124$ & 24,88 & 17,741 & 18,99 \\
\hline 5 & 26 & 6 & 30 & 130,85 & $-0,3447$ & 12,77 & 5,541 & 8,34 \\
\hline 6 & 32 & 6 & 30 & 214,34 & $-0,3013$ & 14,26 & 8,531 & 10,89 \\
\hline 7 & 26 & 9 & 30 & 199,24 & $-0,3257$ & 13,13 & 7,091 & 10,02 \\
\hline 8 & 32 & 9 & 30 & 263,97 & $-0,2451$ & 17,42 & 8,005 & 13,30 \\
\hline 9 & 29 & 7,5 & 25 & 241,77 & $-0,2778$ & 16,09 & 8,687 & 14,12 \\
\hline 10 & 29 & 7,5 & 25 & 243,12 & $-0,2755$ & 16,15 & 9,009 & 14,17 \\
\hline 11 & 29 & 7,5 & 25 & 243,98 & $-0,2746$ & 16,23 & 8,726 & 14,24 \\
\hline
\end{tabular}

dependentes, onde os coeficientes em negrito são os efeitos estatisticamente significativos ao nível de $95 \%$ de confiança.

$$
\begin{aligned}
& R_{p}=254,37-38,05^{\star} U+27,14^{\star} V a-56,56^{\star} V s-4,098^{*} \\
& U^{*} V a-1,00^{\star} U^{*} V s-2,36^{*} V a^{*} V s-0,591 I^{*} V s^{*} T x
\end{aligned}
$$

$$
\begin{aligned}
& E_{\text {corr }}=-0,274+0,0277^{*} U-0,014^{\star} V a-0,029 V s-0,0031^{*} \\
& U^{\star} V a+0,0032^{*} U^{*} V s+0,0039^{*} V a^{\star} V s+0,006 U^{*} V a^{\star} V s
\end{aligned}
$$

\section{Efeitos das variáveis sobre a resistência à polarização $\left(\mathbf{R}_{\mathrm{p}}\right)$}

Observa-se pelos resultados apresentados na Tabela 9 que os valores da Resistência à polarização $\left(\mathrm{R}_{\mathrm{p}}\right)$ variaram de 130,85 $\mathrm{K} \Omega$ a 375,56 K $\Omega$. Através do diagrama de Pareto da Figura 11a, observa-se que a tensão, U, velocidade de alimentação, Va e a velocidade de soldagem, Vs, apresentaram influência significativa na variável de resposta resistência à polarização, $\mathrm{Rp}$, sendo a velocidade soldagem a com maior efeito. O sinal negativo da coluna do gráfico indica que a maior resistência a polarização é atingida para menores valores da velocidade de soldagem.
Diante das informações apresentadas, foi construída a superfície de resposta, Fig. 11b, mantendo-se a velocidade de alimentação de $9 \mathrm{~m} / \mathrm{min}$, variando os valores da tensão no intervalo de $26 \mathrm{~V}$ a $32 \mathrm{~V}$ e a velocidade soldagem variando no intervalo de $20 \mathrm{~cm} / \mathrm{min}$ a $30 \mathrm{~cm} / \mathrm{min}$.

A Fig. 11b mostra o efeito dos valores da velocidade de soldagem e da tensão em função da resistência à polarização dos revestimentos. Pode-se observar que com a elevação da velocidade de soldagem e diminuição da tensão, ocorre o aumento das propriedades anti-corrosivas (resistência à polarização), atingindo um valor máximo aproximadamente de $380 \mathrm{~K} \Omega$. Este valor está próximo do valor experimental obtido no experimento 4 nas mesmas condições que é de 375,56 K $\Omega$. A Tabela 10 apresenta os dados resultantes da análise de variância (ANOVA), teste F e coeficientes de determinação $\left(\mathrm{R}^{2}\right)$.

Portanto os dados da Tabela 10 informam que o modelo apresentado na Equação 6 tem coeficiente de determinação $\left(\mathrm{R}^{2}\right)$ igual a 98,76 \% das variações obtidas explicado pelo modelo, com valor da razão de $\mathrm{F}_{\text {calculado }}$ por $\mathrm{F}_{\text {tabelado }}$ igual a 3,86 indicando que o modelo é estatisticamente significativo com 95\% de confiança ${ }^{(13)}$. 
A Variável de resposta: resistência à polarização $R_{p}$

(3) $\mathrm{Vs}(\mathrm{cm} / \mathrm{min})$ $-11,9176$

$(1) \mathrm{U}(\mathrm{V})$<smiles>C1CCCC1</smiles>
8,019091

(2) $\mathrm{Va}(\mathrm{m} / \mathrm{min})$

5,719268

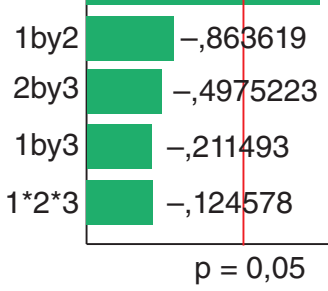

Efeito estimado padronizado (valor absoluto)

B

Superfície de resposta: resistência à polarização $R_{p}$

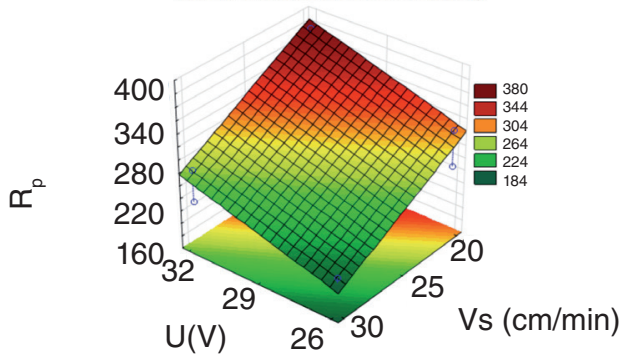

Figura 11: (A) Diagrama de Pareto dos efeitos para resistência a polarização e (B) Superfície de resposta da resistência à polarização sob a influência da Tensão versus Velocidade de soldagem usando $9 \mathrm{~m} / \mathrm{min}$ de Velocidade de alimentação.

Tabela 10: Resultados da ANOVA para Resistência à Polarização.

\begin{tabular}{|c|c|c|c|c|}
\hline Fator & SQ & GL & MQ & Fcalculado \\
\hline Regressão & 43265,27 & 7 & 6180,75 & 34,30 \\
\hline Resíduo & 540,59 & 3 & 180,19 & \\
\hline F.Ajuste & 538,11 & 1 & 538,11 & \\
\hline Erro Puro & 2,48 & 2 & 1,24 & \\
\hline Total & 43805,86 & 10 & & \\
\hline R $^{2}$ & $98,76 \%$ & & & \\
\hline F tabelado & 8,89 & & Fcalc / Ftab $=$ & 3,86 \\
\hline
\end{tabular}

\section{Efeitos das variáveis sobre o potencial de corrosão $\left(\mathrm{E}_{\text {corr }}\right)$}

Os resultados apresentados na Tabela 9 para os valores do Potencial de corrosão, $\mathrm{E}_{\text {corr }}$ variaram de $-0,345 \mathrm{~V}$ a $-0,212 \mathrm{~V}$. Resultado semelhante de potencial de corrosão foi encontrado por Zhang et al. ${ }^{(11)}$. Observa-se na Fig. 12a, que a tensão, U, a velocidade de alimentação, Va e a velocidade de soldagem, Vs, apresentaram influência significativa na variável de resposta, sendo a velocidade de soldagem com maior influência no potencial de corrosão, $\mathrm{E}_{\text {corr }}$, estando com valor negativo na coluna do diagrama, indicando que o $\mathrm{E}_{\text {corr }}$ aumenta com a diminuição da velocidade de soldagem. Por outro lado, a tensão e velocidade de alimentação estando com o valor positivo na coluna do diagrama, indicam que o valor de $\mathrm{E}_{\text {corr }}$ aumenta com a elevação da tensão e da velocidade de alimentação.
A

Variável de resposta: potencial de corrosão $\mathrm{E}_{\text {corr }}$

(3) $\mathrm{Vs}(\mathrm{cm} / \mathrm{min})$ $-47,2475$

$(1) \mathrm{U}(\mathrm{V})$
$(2) \mathrm{Va}(\mathrm{m} / \mathrm{min})$ 44,33415

$1^{*} 2^{*} 3$ $1 * 2 * 3$
$2 b y 3$ 23,74146

\begin{tabular}{l|l|l}
$\begin{array}{l}\text { 1by3 } \\
\text { 1by2 }\end{array}$ & $\begin{array}{l}5,176109 \\
5,08329\end{array}$ \\
\hline $\mathrm{p}=0,05$
\end{tabular}

Efeito estimado padronizado (valor absoluto)

B

Superfície de resposta: potencial de corrosão $\mathrm{E}_{\mathrm{cor}}$

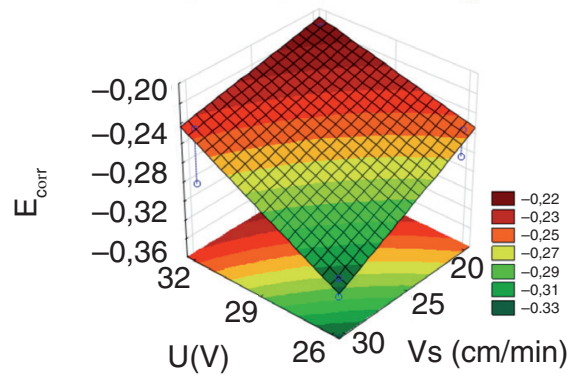

Figura 12: (A) Diagrama de Pareto dos efeitos para potencial de corrosão e (B) Superfície de resposta do Potencial de Corrosão, $\mathrm{E}_{\text {corr }}$, sob a influência da velocidade de soldagem versus tensão usando $9 \mathrm{~m} / \mathrm{min}$ de Velocidade de alimentação.

Com as informações apresentadas, foi construída a superfície de resposta mantendo-se a velocidade alimentação de $9 \mathrm{~m} / \mathrm{min}$, variando os valores da velocidade soldagem variando no intervalo de $20 \mathrm{~cm} / \mathrm{min}$ a $30 \mathrm{~cm} / \mathrm{min}$ e a Tensão no intervalo de 26 V a 32 V. A Fig. 12b mostra o efeito dos valores da velocidade soldagem e da tensão em função do potencial de corrosão dos revestimentos. Assim observou-se que com a diminuição da velocidade de soldagem e elevação da tensão ocorre o aumento no valor do $\mathrm{E}_{\text {Corr }}$ atingindo um valor máximo aproximadamente de $-0,210$ V. Este valor está próximo do valor experimental obtido no experimento 4 nas mesmas condições que é de $-0,212 \mathrm{~V}$. A Tabela 11 apresenta os dados resultantes da análise de variância (ANOVA), teste F e coeficientes de determinação $\left(\mathrm{R}^{2}\right)$.Portanto, os dados da Tabela 29, informam que o modelo apresentado na Equação 14 tem coeficiente de determinação $\left(R^{2}\right)$ igual a 99,9 \% das variações obtidas explicado pelo modelo, equação 14, e com um valor da razão de $\mathrm{F}_{\text {calculado }}$ por $\mathrm{F}_{\text {tabelado }}$ igual a 79,52 indicando que o modelo é estatisticamente significativo com 95\% de confiança com fins preditivos ${ }^{(13)}$.

\section{Resistência à corrosão}

A avaliação da resistência à corrosão dos revestimentos foi conduzida pela técnica de polarização potenciodinâmica linear (PPL) e, para confirmação, utilizou-se a técnica de espectroscopia 
de impedância eletroquímica (EIE). A Fig. 13(a) apresenta as curvas de polarização potenciodinâmica dos experimentos 4 e 5 , as quais apresentaram a maior e a menor diluição, 24,88 e $12,77 \%$, dentre os 11 experimentos realizados. Assim o experimento 4 com maior diluição e teor de ferro, apresentou potencial de corrosão mais positivo que a amostra do experimento 5 com menor diluição, onde indica maiores propriedades anti-corrosivas. Para efeito de confirmação dos resultados das curvas de PPL sobre a resistência à corrosão, foram realizadas medidas de espectroscopia de impedância eletroquímica. A Fig. 13 (b) mostra o diagrama de impedância dos revestimentos com Inconel 625 dos mesmos experimentos avaliadas por PPL.

A Fig. 13(b) apresenta o diagrama de impedância, o qual indica que quanto maior for arco, maior é o valor da resistência à polarização, Rp, cujo valor é tomado no eixo das abscissas traçando-se

Tabela 11: Resultados da ANOVA para Potencial de corrosão

\begin{tabular}{|c|c|c|c|c|}
\hline Fator & SQ & GL & MQ & Fcalculado \\
\hline Regressão & 0,0155 & 7 & 0,00222 & 706,94 \\
\hline Resíduo & 0,0000 & 3 & 0,00000 & \\
\hline F.Ajuste & 0,000004 & 1 & 0,00000 & \\
\hline Erro Puro & 0,0000 & 2 & 0,00000 & \\
\hline Total & 0,0155 & 10 & & \\
\hline R $^{2}$ & $99,90 \%$ & & & \\
\hline F tabelado & 8,89 & & Fcalc / Ftab $=$ & 79,52 \\
\hline
\end{tabular}

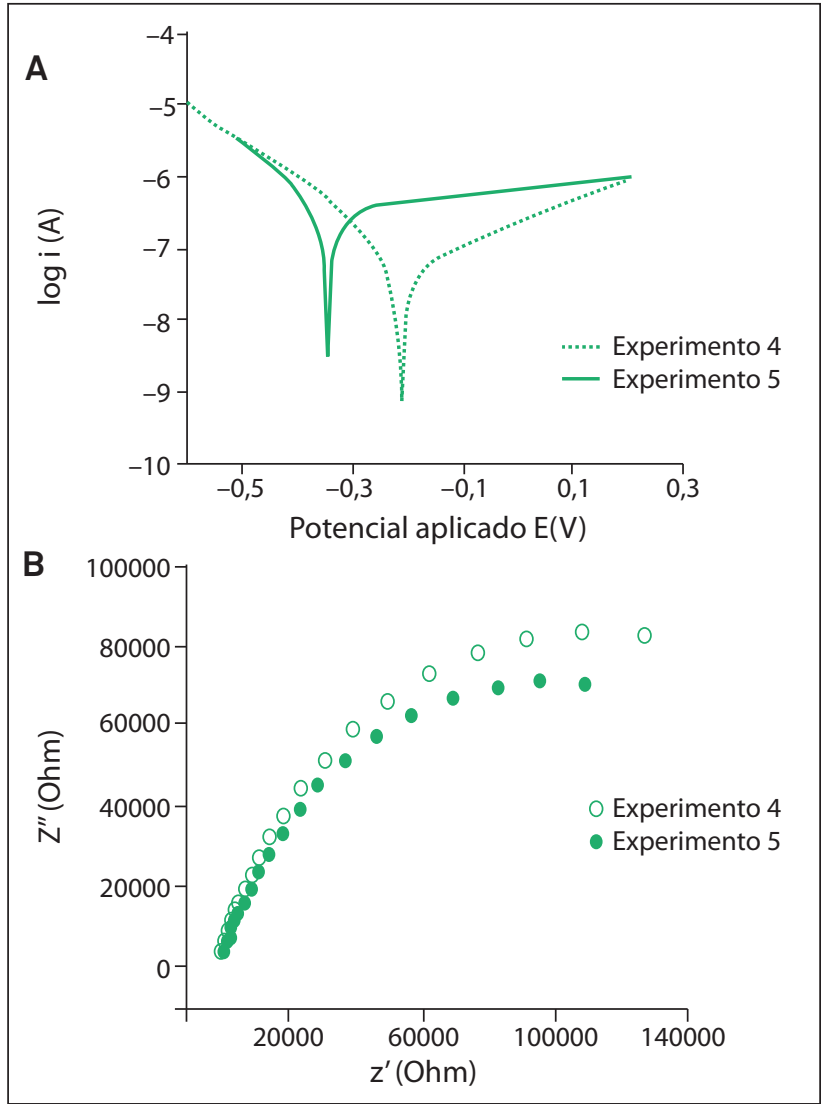

Figura 13: (a) Curva de polarização dos experimentos 4 e 5 , (b) Diagrama de impedância dos experimentos 4 e 5 . um semicírculo que melhor se ajuste à curva e maior será a resistência à corrosão do material exposto ao meio corrosivo ${ }^{(30,31)}$

Assim, os resultados obtidos pela técnica de espectroscopia de impedância eletroquímica confirmam os valores encontrados pela PPL, que indicou que os experimentos com maior nível de diluição e maior teor de Fe apresentaram maior resistência à polarização.

Tais resultados são contrários aos resultados encontrados por alguns autores ${ }^{(29,32)}$, que encontraram resultados que mostram que quanto menor a diluição e menor o teor de ferro maior a resistência à corrosão.

Segundo Sousa et $\mathrm{al}^{(33)}$,esta maior resistência à corrosão em revestimentos aplicados com maior energia de soldagem, apesar da maior diluição e, consequentemente maior teor de Fe na superfície, se deve a velocidade de resfriamento menor e, consequentemente, ao favorecimento adequado do balanceamento químico entre as fases, que supera o aspecto do maior teor de Fe na superfície. A explicação também pode está relacionada com o nível de tensões residuais compressivas, ou seja, quanto mais elevada à energia de soldagem maior será o nível de tensões residuais compressivas, consequentemente maior a resistência à corrosão. Resultado similar foi obtido por Melo ${ }^{(34)}$, que obteve na deposição por processo SAW, Submerged Arc Welding, um aumento de $-41 \mathrm{MPa}$ na tensão residual compressiva ao se aumentar a energia de soldagem 12,90 KJ/cm para $14 \mathrm{KJ} / \mathrm{cm}$, resultando em uma resistência a polarização de $194 \mathrm{~K} \Omega(12,90 \mathrm{KJ} / \mathrm{cm})$ e $206 \mathrm{~K} \Omega(14 \mathrm{KJ} / \mathrm{cm})$.

\section{CONCLUSÕES}

Com base nos resultados experimentais obtidos neste trabalho as conclusões são as seguintes:

Utilizado o processo de soldagem GMAW foi obtido com sucesso revestimento s de boa qualidade. Foi observado que os melhores resultados para o reforço foi obtido com diminuindo a velocidade de soldagem, aumento da tensão e da velocidade de alimentação obtendo um reforço de aproximadamente $6,3 \mathrm{~mm}$.

Foi observado o efeito da velocidade de soldagem, velocidade de alimentação e tensão na largura dos cordões de solda. Com o aumento da tensão e diminuição da velocidade de soldagem foram obtidos cordões largos o que são excelentes para revestimentos obtidos pelo processo de soldagem. Obtendo um índice de convexidade de aproximadamente $31 \%$ o que é recomendado para esse tipo de processo.

Foram obtidos revestimentos com diluição variando de $12,77 \%$ à $24,88 \%$. Foi observado que os melhores valores de diluição foram obtidos como aumento da velocidade de soldagem (30 cm/min) e diminuição da tensão $(26 \mathrm{~V})$ obtendo um valor de diluição de $12,77 \%$.

Foi avaliado a microdureza desde o metal base passando pela zona termicamente afetada até o metal de solda. Foi observado que a microdureza do metal de solda é maior do que a do metal 
de base. Na zona termicamente afetada ocorreu uma variação da dureza com relação ao metal de base e o metal de solda. Um aumento de 13,51 HV no valor médio da microdureza da ZTA, ocorre ao reduzir a energia de soldagem de $\mathrm{H}=18,99 \mathrm{KJ} / \mathrm{cm}$ para $\mathrm{H}=8,34 \mathrm{~kJ} / \mathrm{cm}$;

Para as medidas de corrosão foi observado que o potencial de corrosão obtido foi de $-0,212 \mathrm{~V}$. Os melhores valores de potencial de corrosão e de resistência de polarização foram obtidos com o aumento da tensão e diminuição da velocidade de soldagem. Os cordões obtidos nestas condições foram os que apresentaram os melhores resultados para o reforço, largura e índice de convexidade.

\section{REFERÊNCIAS}

1. BILÓ, T. C.; ALMEIDA, C.; CECCOPIERI, W.; BELMIRO, B.; DE CASTRO, M., Methods for estimating the velocities of the Brazil Current in the pre-salt reservoir area off southeast Brazil ( $23 \otimes \mathrm{S}$ $26 \otimes S$ ), 2014. doi:10.1007/s10236-014-0761-2.

2. MELO, C. L.; THEDY, E. A.; ROCHA, P. S.; DE ALMEIDA, A. S.; MUSSE, A. P., The challenges on the CCGS monitoring in the development of Santos Basin Pre-salt Cluster, Energy Procedia. 4 (2011) 3394-3398. doi:10.1016/j.egypro.2011.02.262.

3. MOREIRA, J. R.; PACCA, S.A.; PARENTE,V., The future of oil and bioethanol in Brazil, Energy Policy. 65 (2014) 7-15. doi:10.1016/j. enpol.2013.09.055.

4. PETROBRAS, Plano de Negócios e Gestão 2013-2017, (2013). http://www.petrobras.com.br/pt/quem-somos/estrategiacorporativa/plano-de-negocios.

5. ALIZADEH, M.; BORDBAR, S., The influence of microstructure on the protective properties of the corrosion product layer generated on the welded API X70 steel in chloride solution, Corros. Sci. 70 (2013) 170-179. doi:10.1016/j.corsci.2013.01.026

6. BEIDOKHTI, B.; DOLATI, A.; KOUKABI, A. H., Effects of alloying elements and microstructure on the susceptibility of the welded HSLA steel to hydrogen-induced cracking and sulfide stress cracking, Mater. Sci. Eng. A. 507 (2009) 167-173. doi:10.1016/j. msea.2008.11.064

7. ANTUNES, R. A.; ANTONIO, C.; DE ALMEIDA, V., Influence of Testing Temperature on the Corrosion Behavior of Api $5 \mathrm{~L}$ X70 Pipeline, 4 (2013) 3252-3256.

8. OSKUIE, A. A.; SHAHRABI, T.; SHAHRIARI, A.; SAEBNOORI, E., Electrochemical impedance spectroscopy analysis of $X 70$ pipeline steel stress corrosion cracking in high $\mathrm{pH}$ carbonate solution, Corros. Sci. 61 (2012) 111-122. doi:10.1016/j.corsci.2012.04.024.

9. ZHANG, L.; LI, X.; DU, C.; HUANG, Y., Effect of applied potentials on stress corrosion cracking of $X 70$ pipeline steel in alkali solution, Mater. Des. 30 (2009) 2259-2263. doi:10.1016/j. matdes.2008.09.019.

10. DAVIS, J., Hardfacing, weld cladding, and dissimilar metal joining, in: A. International (Ed.), Met. HANDBOOK. Welding, Brazing Solder., 10a ed., Ohio, 1993.

11. ZIKIN, A.; BADISCH, E.; HUSSAINOVA, I.; TOMASTIK, C.; DANNINGER, H., Characterisation of TiC-NiMo reinforced $\mathrm{Ni}$ based hardfacing, Surf. Coatings Technol. 236 (2013) 36-44. doi:10.1016/j.surfcoat.2013.02.027.
12. MENG, X.; QIN, G.; ZHANG, Y.; FU, B.; ZOU, Z., High speed TIG-MAG hybrid arc welding of mild steel plate, J. Mater. Process. Technol. 214 (2014) 2417-2424. doi:10.1016/i. jmatprotec.2014.05.020.

13. ELSAWY, A. H., Characterization of the GTAW fusion line phases for superferritic stainless steel weldments, J. Mater. Process. Technol. 118 (2001) 127-131. doi:10.1016/S0924-0136(01)00887-1.

14. SONG, J. L.; LIN, S. B.; YANG, C. L.; MA, G. C.; LIU, H., Spreading behavior and microstructure characteristics of dissimilar metals TIG welding-brazing of aluminum alloy to stainless steel, Mater. Sci. Eng. A. 509 (2009) 31-40. doi:10.1016/j.msea.2009.02.036.

15. BîRDEANU, A. V.; CIUCØ, C.; PUICEA, A., Pulsed LASER(micro)TIG hybrid welding: Process characteristics, J. Mater. Process. Technol. 212 (2012) 890-902. doi:10.1016/j. jmatprotec.2011.11.014.

16. ALFARO, S. C. A.; CARVALHO, G. C.; DE MELO, S. A., Stand off's indirect estimation in GMAW, J. Mater. Process. Technol. 157-158 (2004) 3-7. doi:10.1016/j.jmatprotec.2004.09.002.

17. SONG, K. H.; NAKATA, K., Effect of precipitation on post-heattreated Inconel 625 alloy after friction stir welding, Mater. Des. 31 (2010) 2942-2947. doi:10.1016/j.matdes.2009.12.020.

18. DINDA, G. P.; DASGUPTA, A. K.; MAZUMDER, J., Laser aided direct metal deposition of Inconel 625 superalloy: Microstructural evolution and thermal stability, Mater. Sci. Eng. A. 509 (2009) 98104. doi:10.1016/j.msea.2009.01.009.

19. CORREIA, D. S.; GONÇALVES, C. V.; DA CUNHA, S. S. FERRARESI, V. A., Comparison between genetic algorithms and response surface methodology in GMAW welding optimization, J. Mater. Process. Technol. 160 (2005) 70-76. doi:10.1016/j. jmatprotec.2004.04.243.

20. SANTANA, R. A. C.; PRASAD, S.; MOURA, E. S.; CAMPOS, A. R.N.; SILVA, G. P.; LIMA-NETO, P., Studies on electrodeposition of corrosion resistant Ni-Fe-Mo alloy, J. Mater. Sci. 42 (2007) 22902296. doi:10.1007/s10853-006-0615-5.

21. SANTANA, R. A. C.; PRASAD, S.; CAMPOS, A. R. N.; ARAÚJO, F. O.; DA SILVA, G. P.; DE LIMA-NETO, P., Electrodeposition and corrosion behaviour of a Ni-W-B amorphous alloy, J. Appl. Electrochem. 36 (2006) 105-113. doi:10.1007/s10800-005-9046-2.

22. OLIVEIRA, A. L. M.; COSTA, J. D.; DE SOUSA, M. B.; ALVES, J. J. N.; CAMPOS, A. R. N.; SANTANA, R. A. C.; et al., Studies on electrodeposition and characterization of the $\mathrm{Ni}-\mathrm{W}-\mathrm{Fe}$ alloys coatings, J. Alloys Compd. 619 (2015) 697-703. doi:10.1016/j. jallcom.2014.09.087.

23. N-1707, PETROBRÁS, No TitleProjeto de vaso de pressão com revestimento, (2011).

24. SCOTTI, V.; PONOMAREV, A., Soldagem MIG/MAG: Melhor entendimento, melhor desempenho, São Paulo -SP - Brasil, 2008.

25. BARROS NETO, R. E.; SCARMINIO, B.; BRUNS, I. S., Planejamento e otimização de experimentos, 2a Edição, Campinas-SP, 1996.

26. SILVA, C. R., V.A. FERRARESI, A. SCOTTI, A quality and cost approach for welding process selection, J. Brazilian Soc. Mech. Sci. Eng. 22 (2000). doi:http://dx.doi.org/10.1590/S010073862000000300002

27. PESSOA, A. R. P., Revestimento de ligas de níquel pelo processo MIG/MAG com Transferência por Curto-Circuito, Universidade Federal do Ceará, 2009.

28. KEJELIN, N. Z.; BUSCHINELLI, A. J. A.; BOHÓRQUEZ, C. E. N., Soldagem Dissimilar do Aço X-60 com Inconel 625, (2013). http:// 
www.labsolda.ufsc.br/noticias/2007/soldagem_dissimilar.pdf (accessed December 12, 1BC)

29. BATISTA, V. R., Influência dos parâmetros de soldagem sobre as características de revestimentos de liga de níquel aplicados em aços API 5L Gr B pelo processo arco submerso., Universidade Federal de Campina Grande, Campina Grande, 2011.

30. GENTIL, V., Corrosão, 5a edição, Rio de Janeiro RJ, 2007.

31. JAMBO, S.; FÓFANO, H. C. M., Corrosão: Fundamentos, Monitoração e Controle, Rio de Janeiro RJ, 2008.

32. SILVA, M. M., Avaliação da compatibilidade metalúrgica e da resistência à corrosão de revestimentos da liga AWS ER
NiCrMo-4 aplicados por soldagem SAW sobre o aço API 5L Gr B, Universidade Federal de Campina Grande, 2013.

33. SOUZA, C. S.; LINS, V. D. F. C.; DA SILVEIRA, D. M.; COSTA, C. G. F.; CARDOSO JUNIOR, R.; CAMPOS, F. R.; et al., Avaliação da soldagem multipasse de chapas espessas de aços inoxidáveis lean duplex UNS S32304 soldadas pelos processos SMAW, GMAW e FCAW - Parte II: Resistência à Corrosão, Soldag. E Insp. 18 (2013) 257-267. doi:10.1590/ S0104-92242013000300008.

34. MELO, R.H.F., Avaliação da Influência do processo e dos parâmetros de soldagem sobre a resistência à corrosão de revestimentos de aço inoxidáveis AWS e 308-L T1 aplicados em aços ASTM A36, Universidade Federal de Campina Grande, 2013. 